\title{
METODOLOGÍAS DE ENSEÑANZA APRENDIZAJE DE LA EXPRESIÓN ESCRITA A ESTUDIANTES DE PRIMER INGRESO EN LA URACCAN, RECINTO BILWI
}

Licda. Carmen Elena Rossman Tejada ${ }^{[1]}$

Tutora : MA. María Elena Watson Pérez ${ }^{\text {[2] }}$

\section{Resumen}

En la actualidad la población estudiantil ha presentado cada vez más dificultades de expresión escrita. Estos problemas se deben en alguna medida al sistema educativo, al entorno familiar, al nivel socioeconómico y a la baja calidad en la lecto-escritura que repercute en los jóvenes que cursan los diferentes niveles de estudio y posteriormente la educación superior. Con este estudio se pretendería contribuir al mejoramiento del proceso metodológico para la enseñanza de la ciencia y arte de la expresión escrita, al ser esta una problemática entre los docentes y estudiantes en la universidad URACCAN Recinto Bilwi.

El enfoque se ha orientado al interaccionismo simbólico, análisis del proceso educativo en el cual interactúa. Se aplicó la entrevista abierta para obtener información relevante sobre el tema en estudio y observaciones en el aula de clase mediante el cual se percibió los momentos del proceso educativo.

Los hallazgos confirman que existen limitantes en la expresión escrita y en la ejercitación que orienta el docente como parte del desarrollo de habilidades que deben adquirir en la redacción. El personal docente manifestó que no hay una metodología definida para la enseñanza de la expresión escrita. Eso ha incidido en la aplicación de diferentes estrategias que tienen como objetivo que los estudiantes adquieran esas habilidades que le permitan expresar sus ideas con coherencia. Los estudiantes conforman una diversidad étnica, cultural y lingüística que requiere necesariamente de una atención educativa pertinente que contribuya al desarrollo de dichas habilidades en el nivel de la educación superior.

Palabras clave: metodología de la enseñanza aprendizaje, escritura, Recinto Bilwi.

\footnotetext{
${ }^{[1]}$ Docente de Idioma Español, URACCAN Recinto Bilwi. Máster en Docencia Universitaria. carmenross65@latinmail.com.

[2] Coordinadora del Área de Humanidades URACCAN Recinto Bilwi. Máster en Estudios Interdisciplinarios. mwatsonp2002@yahoo.com.
} 


\section{Summary}

Currently the student population has been presenting more difficulties in writing. These problems in some extent are due to the education system, the family environment, socioeconomic level and also the low quality of reading and writing, which affects young people who attend the different levels of study and then higher education. This study seeks to contribute to the improvement of the methodological process for the teaching of science and art of writing, as this is a problem between teachers and students at the URACCAN University, Bilwi Campus.

The focus was oriented using the symbolic interactionism and the analysis of the educational process in which it interacts. Open interviews were applied in order to gather relevant information on the topic, also observations in the classroom which allowed to watch different moments of the educational process.

The findings confirm that there are limitations in writing and in the exercise that guide the teacher as part of the development of skills that they should acquired in the writing. The teachers expressed that there is no defined methodology for the teaching of writing. This has affected the implementation of different strategies that aims at students acquiring those skills in order to express their ideas coherently. Students form an ethnic, cultural and linguistic diversity that necessarily requires a pertinent educational service to help develop these skills at the level of higher education.

Keywords: Teaching-learning methodology, writing, Bilwi Campus.

\section{Introducción}

El presente trabajo de investigación titulado: Metodologías de enseñanza aprendizaje para la expresión escrita a estudiantes de primer ingreso de Administración de Empresa. Se aborda dentro del campo de la educación, que facilita la URACCAN Recinto Bilwi.

El recinto URACCAN-Bilwi oferta varias carreras, en este estudio se tomó como referencia la carrera de Administración de Empresa, debido a que las limitantes presentadas en la expresión escrita por los y las estudiantes que ingresan a dicha carrera, es una problemática muy sentida por los docentes que imparten la asignatura de español y los docentes que imparten las otras asignaturas.

Al tener la expresión escrita un nivel de complejidad en los y las estudiantes de primer ingreso, se consideró importante realizar este estudio dada la importancia que tiene este componente en el estudio del español como lengua oficial de enseñanza y que ellos y ellas apliquen, las reglas ortográficas, la sintaxis, semántica y las normas gramaticales para un buen escrito. 


\section{EDUCACIÓN}

En nuestro contexto considerar la particularidad lingüística de los y las estudiantes es muy importante para el docente y las instancias de dirección de la universidad, porque el y la estudiante maneja más de una lengua es decir su lengua materna y las otras lenguas con la cual va interactuando en su entorno de una manera oral mediante la relación familiar y la comunidad.

Por tanto, verse en determinado momento en un escenario donde debe aprender y escribir en otra lengua (el español) que no es la que él utiliza en su comunicación cotidiana, representa para el o la docente y los estudiantes un reto muy complejo.

Se utilizaron como instrumento para la recopilación de la información, guías de entrevistas que fueron aplicadas a los docentes y estudiantes, guías de observación al docente durante el desarrollo del proceso de enseñanza aprendizaje en el aula, cada uno de estos instrumentos permitieron obtener las informaciones de manera objetiva y confiable que dieron salida a los objetivos del trabajo investigativo.

Sobre el tema que me he propuesto investigar no hay estudios al respecto, pero si algunos que se relacionan con la problemática de la expresión escrita, a como señalan Young y Gutiérrez (2007) "La enseñanza de la ortografía acentual no se ha realizado por pasos, no se ha ejercitado adecuadamente y por ende no se ha aprendido para aplicarse", también explicaron que "el multilingüismo es otro aspecto relevante dado que los y las estudiantes hablan más de una lengua y debido a esto tienen problemas para discriminar auditivamente los sonidos y las palabras".

Debido a lo antes expuesto nace el interés por realizar este estudio, tomando en cuenta que el estudiante universitario tiene muchas exigencias académicas que lo remiten continuamente a la redacción de documentos.

Ante esto se plantean algunas estrategias metodológicas que faciliten alternativas que contribuyan al mejoramiento de la expresión escrita de los y las estudiantes y el proceso de enseñanza aprendizaje que facilita el docente.

\section{Objetivos}

\section{Objetivo general:}

Contribuir al mejoramiento del proceso metodológico en la enseñanza-aprendizaje de la expresión escrita a estudiantes de primer ingreso de la carrera de Administración de Empresa. URACCAN - Bilwi, 2009. 


\section{Objetivos específicos:}

1. Identificar las metodologías utilizadas por el/la docente para la enseñanzaaprendizaje de la expresión escrita a estudiantes de primer ingreso de la carrera de administración de Empresa.

2. Describir las limitaciones que presentan los y las estudiantes en la expresión escrita.

3. Plantear algunas estrategias metodológicas para la enseñanza-aprendizaje de la expresión escrita a estudiantes de primer ingreso en la carrera de Administración de Empresa URACCAN Bilwi.

\section{Metodología}

\section{Tipo de estudio:}

Este estudio es cualitativo. Su enfoque corresponde al interaccionismo simbólico, dado que el centro del análisis está en el estudio social de los estudiantes y docentes durante el proceso de enseñanza aprendizaje, en el cual interactúan mediante la comunicación.

Esta comunicación se propicia por el lenguaje y otros símbolos creando y produciendo significados para comprender la problemática del cómo enseñar y el aprender la expresión escrita casi en su totalidad a grupos de estudiantes Miskitu que tienen como primera lengua el Miskitu. En este sentido, mi análisis se encamina a tratar de interpretar si son pertinentes las metodologías implementadas actualmente en la enseñanza aprendizaje de la expresión escrita.

\section{Variables de estudio:}

- Expresión escrita.

- Metodología utilizada por la docente en la enseñanza aprendizaje de la expresión escrita.

- Limitaciones en la expresión escrita.

- Estrategias metodológicas para la enseñanza aprendizaje de la expresión escrita.

\section{Instrumentos:}

1. Guías de entrevistas a docentes que imparten clase en el primer año de la carrera.

2. Guías de entrevistas a los y las estudiantes seleccionados para la muestra del estudio.

3. Guías de observación de clase al docente. 


\section{Procesamiento y Análisis de datos}

Primeramente se organizaron y ordenaron los diferentes instrumentos aplicados, considerando para estos los objetivos planteados en el estudio, todas las informaciones obtenidas de las diferentes fuentes que conformaron la muestra del estudio una vez organizadas, se procedió a la realización de una lectura analítica, reflexiva, exhaustiva para explorar y percibir en un primer momento lo que expresaron, opinaron y dijeron cada uno de los informantes. Este procedimiento permitió posteriormente obtener elementos para construir mediante las informaciones obtenidas, ideas sobre la temática estudiada y así identificar los hallazgos más relevantes.

Así también se realizó la revisión e interpretación de las diferentes respuestas dadas de forma independiente por instrumentos aplicados, se compararon para discernir la afinidad entre las informaciones recopiladas, diferenciando el tipo de participantes y sus expresiones.

Posteriormente se tomaron en cuenta las observaciones realizadas en el aula de clase sobre el desarrollo del proceso de enseñanza aprendizaje, estos insumos que se obtuvieron mediante los diferentes instrumentos aplicados fueron claves para la discusión y análisis de los resultados encontrados con los cuales se procedió a la redacción del informe final, el que una vez finalizado será defendido ante un tribunal.

\section{Resultados y discusión}

\section{Metodologías que implementan los docentes para la enseñanza - aprendizaje de la expresión escrita}

La mayoría de las informantes coincidieron cuando expresaron que no podrían definir una metodología porque la práctica que han llevado en el aula de clase para la enseñanza de la expresión escrita ha sido en base a estrategias y técnicas en la cual interactúan los estudiantes y ellas.

Se percibe mediante las expresiones dadas por las docentes que la práctica educativa en la cual facilitan la enseñanza aprendizaje para la expresión escrita toman en cuenta al estudiante cuando les piden:

que expresen situaciones que ocurren en el aula, que sea de su entorno, que redacten párrafos o composiciones, informes de la actividad realizada en el aula y que expresen sus ideas" lo que se puede relacionar con lo planteado por Matus (2008) que "redactar es exponer por medio de la palabra escrita todo lo relacionado con los quehaceres de la vida cotidiana. 


\section{Limitantes en la expresión escrita de los y las estudiantes}

Las limitantes encontradas señalan que los y las estudiantes no desarrollan las habilidades para una buena escritura por la falta de coherencia en el escrito, desconocimiento de las categorías gramaticales, de la ortografía acentual y puntual.

Lo anterior referido por estudiantes y docentes se pudo vivenciar durante las observaciones que se realizaron en el aula de clase en la cual interactuaban ambos, se logró ver en un momento de cómo ejercitan la expresión escrita, la cual fue a través de la presentación de sus escritos en papelógrafos en los que se pudo visualizar, que no hacen uso de la ortografía acentual y puntual, sus expresiones son incoherentes, unen los artículos con las preposiciones. Reflexionando y analizando lo que expresaron y se observó en el aula de clase por los informantes y actores del proceso enseñanza aprendizaje es importante considerar a las autoras como Gutiérrez y Young (2007) quienes plantean que la enseñanza de la ortografía acentual no se ha realizado por pasos, no se ha ejercitado adecuadamente y por ende no se ha aprendido para aplicarse.

\section{Estrategias metodológicas para la enseñanza aprendizaje de la expresión escrita}

Los docentes coinciden en que se deben emplear estrategias que motiven al estudiante para que pueda desarrollar las habilidades en la expresión escrita. Y superar las limitaciones que presentan. Al respecto, Silva, citado por Brookes y Grundy (1998) dice que "el rol del profesor es ayudar al estudiante a desarrollar estrategias viables para la generación de ideas, en las clases hay que ejercitar la comunicación escrita tratando de ofrecer al alumno los recursos estratégicos que le permitan perfeccionarla".

\section{Conclusiones}

En base al análisis y discusión de los resultados obtenidos mediante los instrumentos que se aplicaron se llegó a las siguientes conclusiones:

No hay una metodología única para la enseñanza aprendizaje de la expresión escrita, pero si una gran experiencia en la aplicación de estrategias y técnicas como; la facilitación de frases motivadoras que incentivan la redacción de oraciones, párrafos y composiciones, revisión y corrección de los trabajos escritos en conjunto, y de manera individual para su evaluación y retroalimentación, comentarios de lecturas y la recreación de textos para el desarrollo del pensamiento crítico y la creatividad.

Mediante las estrategias implementadas por los y las docentes los estudiantes mejoran en parte su expresión escrita lo que nos indica que no desarrollan las habilidades propias de una buena redacción, por lo que se hace necesario implementar metodologías pertinentes que orienten la enseñanza aprendizaje del español como una segunda lengua. 


\section{EDUCACIÓN}

Las limitantes encontradas señalan que los y las estudiantes no desarrollan las habilidades para una buena escritura por la falta de coherencia en el escrito, desconocimiento de las categorías gramaticales, de la ortografía acentual y puntual.

Los estudiantes que tienen como lengua materna el miskitu, creole y mayangna presentan mayores debilidades, en su expresión escrita lo que podría relacionarse con las particularidades muy propias en ellos y ellas.

Lo antes señalado respecto a las limitantes de los estudiantes, debe instar a la reflexión y la búsqueda de otras estrategias que promuevan un tratamiento metodológico en el cual se facilite la inserción positiva de estudiantes hablantes de otras lenguas.

Considerando la particularidad de los y las estudiantes y las habilidades que ellos requieren tener, se plantearon algunas estrategias metodológicas que contribuyan a este logro.

\section{Recomendaciones}

- A las instancias de dirección de la universidad

- Dentro de las revisiones y adecuaciones que se hacen a los programas de la asignatura de español, valorar la situación dada en relación a las y los estudiantes que dominan más su lengua materna.

- Capacitar al persona docente en la aplicación de estrategias para la enseñanza del español como segunda lengua.

- Dotar con grabadoras, videos, laminarías a las y los docentes que imparten español para que propicien esos espacios en la cual los y las estudiantes que su lengua materna no es el español, puedan apropiarse de una manera más dinámica de las estrategias que le permitirán desarrollar las habilidades para la expresión escrita.

\section{- Al personal docente}

- Mantener la implementación de estrategias que contribuyan al fortalecimiento de la expresión escrita de las y los estudiantes independientemente de la asignatura que impartan.

- Orientar mucha lectura y escritura con trabajos individuales en todas las asignaturas. 
- Promover los círculos de estudio, competencias, dinámicas y otras actividades motivadoras.

- Brindar aportes técnicos pedagógicos a las instancias de dirección de la universidad como producto de la práctica educativa que desarrolla en el aula de clase con estudiantes que son poseedores de diversas lenguas (miskitu, creolle, mayangna).

\section{- A la comunidad de estudiantes}

- Auxiliarse de su lengua materna, sus vivencias para incidir en sus escritos en la otra lengua con la cual se le facilita el proceso de enseñanza aprendizaje.

- Contribuir mediante su participación activa en la apropiación de las técnicas, estrategias que les facilitan desarrollar habilidades para la expresión escrita.

- Desarrollar hábitos de lectura permanente para el enriquecimiento de un vocabulario amplio que le permitirá expresar ideas, contar con capacidad para desarrollar sus escritos, así como contar con un vocabulario propio de la especialidad.

\section{Referencias}

Cassany, D., (1990). Enfoques didácticos para la enseñanza de la expresión escrita, Comunicación, lenguaje y educación. Madrid.

Jarquín, S. \& Malean, G. (2001). Didáctica del español como segunda lengua. URACCAN Bilwi kamla.

Matus L. R. (2008). Redacción Moderna. 1ra.ed. Managua, Nicaragua.

Rodríguez I. (1996). La expresión escrita. Editorial UCA - Managua.

Venecia, P. (2003) Educación Intercultural y Plurilingüe Tomo 3. Terranova. Managua. 
EDUCACIÓN

\section{Glosario técnico}

\section{Estrategias}

Las estrategias son los procedimientos o recursos utilizados por el agente de enseñanza para promover aprendizajes significativos

\section{Expresión escrita}

Es una de las denominadas destrezas lingüísticas que se refiere a la producción del lenguaje escrito.

\section{Metodologías}

"El conjunto de normas relativas a los métodos de que la educación se vale para cumplir su cometido. Comprende los principios de esos métodos, sus tipos y sus formas de realización"

\section{Lengua materna}

Llamada también L1 o primera lengua. Es la lengua adquirida durante los primeros años de vida y que constituye el instrumento de pensamiento y comunicación del hablante.

\section{Limitaciones}

Impedimento, defecto o restricción que reduce las posibilidades o la amplitud de algo. 